\title{
A switch from high-fat to normal diet does not restore sperm quality but prevents metabolic syndrome
}

\author{
Luís Crisóstomo ${ }^{1,2,3}$, Luís Rato ${ }^{4}$, Ivana Jarak,4, Branca M Silva ${ }^{4}$, João F Raposo ${ }^{5,6}$, \\ Rachel L Batterham ${ }^{7}$, Pedro F Oliveira ${ }^{1,2,3}$ and Marco G Alves ${ }^{1}$ \\ ${ }^{1}$ Department of Microscopy, Laboratory of Cell Biology, and Unit for Multidisciplinary Research in Biomedicine \\ (UMIB), Institute of Biomedical Sciences Abel Salazar (ICBAS), University of Porto, Porto, Portugal, ${ }^{2}$ Department of \\ Genetics, Faculty of Medicine of the University of Porto (FMUP), Porto, Portugal, ${ }^{3}$ i3S - Instituto de Investigação e \\ Inovação em Saúde, University of Porto, Porto, Portugal, ${ }^{4}$ Faculty of Health Sciences, University of Beira Interior, \\ Covilhã, Portugal, ${ }^{5}$ NOVA Medical School - New University Lisbon, Lisbon, Portugal, ${ }^{6}$ APDP - Associação de \\ Protecção dos Diabéticos de Portugal, Lisbon, Portugal and ${ }^{7}$ Centre for Obesity Research, Rayne Institute, Centre for \\ Weight Management and Metabolic Surgery \& National Institute of Health Research, University College London, \\ London, UK
}

Correspondence should be addressed to M G Alves; Email: alvesmarc@gmail.com

\begin{abstract}
In recent decades, the prevalence of metabolic diseases has concomitantly increased with a decline on fertility rates and sperm quality. High-fat diets (HFD) are seldom considered part of the problem, but the molecular mechanisms underlying its effects on male fertility remain poorly understood. Herein we postulated that HFD alter sperm quality. We evaluated the effects of switching from a HFD to a normal diet in early adulthood on metabolic disease onset, testicular metabolism and sperm quality. Thirty-six male C57BL6/J mice were divided in: a control group fed with standard chow; a group fed with HFD for 200 days; and a group fed with HFD for 60 days and then with standard chow $\left(H_{F D}\right)$. Biometric data and whole-body metabolism were assessed. Epididymal sperm was studied for concentration, motility, viability and morphology. ${ }^{1} \mathrm{H}-\mathrm{NMR}$ metabolomics approach was performed on testicular extracts to trace the metabolic changes. Diet switch reduced body weight and fat mass, preventing metabolic syndrome onset. However, sperm viability, motility and morphology were deteriorated by HFD consumption and not restored by diet switch. HFD induced irreversible changes in pyruvate and glutamate metabolism, ethanol degradation and ammonia recycling in testis. Furthermore, $\mathrm{HFD}_{\mathrm{t}}$ changed purine and cysteine metabolism, urea cycle, and glutathione content. Overall, HFD caused irreversible changes in testicular metabolism even after switching to normal diet. HFD feeding until early adulthood decreases sperm quality, which cannot be restored by diet switch or weight loss, even when development of metabolic syndrome is avoided.

Reproduction (2019) 158 377-387
\end{abstract}

\section{Introduction}

Since the second half of the 20th century, the prevalence of metabolic disease has increased worldwide. Obesity and type 2 diabetes mellitus (T2DM) are the most prevalent metabolic diseases, and are regarded as global epidemics by World Health Organization (2000). Obesity and T2DM, are largely caused by lifestyle, particularly sedentary behaviours and poor dietary habits, such as high-fat diets (HFDs). Interestingly, during the same period, several studies report a decline in human fertility rates, and particularly in male reproductive parameters (Hamilton \& Ventura 2006, Skakkebaek et al. 2016). Indeed, couples with overweight and obesity attending fertility clinics have worse reproductive outcomes. Energy balance is crucial for spermatogenesis and overweight men are reported to present poorer sperm quality amongst other reproductive problems
(Oliveira et al. 2017). Similarly, men with T2DM suffer from several reproductive problems, such as microvascular disease. Men attending fertility clinics are often requested to change their eating habits and lose weight to improve their sperm parameters. Nevertheless, few studies report the molecular basis linking food habits, overweight and poor male fertility. So, the efficiency of dietary intervention such as reduced intake of dietary fats and weight loss upon male fertility is unknown.

Male reproductive function demands a considerable amount of energy to be sustained. Thus, metabolic regulation of testicular cells is crucial to maintain spermatogenesis (Rato et al. 2012). The elevated energy content of HFD (and hypercaloric diets) registers a metabolic signature in the body. The first visible effect of hypercaloric diets is the storage of excess energy as fat in white adipose tissue (WAT) pads. This accumulation 
promotes the onset of metabolic disease, translated into glucose intolerance, insulin resistance and insulin deficiency. The rodent model has been long used to carry out experimental designs and test hypotheses that would be impossible to test or take too long in humans, and to avoid the typical confounding factors of human subjects (Dutta \& Sengupta 2016).

In this work, we propose to study the molecular mechanisms by which HFD and transient high-fat diet $\left(\mathrm{HFD}_{\mathrm{t}}\right)$ can alter male reproductive health, such as glucose homeostasis and metabolic changes in testes that compromise sperm quality. We used a C57BL6/J mice model fed with HFD or HFD $\mathrm{H}_{\mathrm{t}}$ and compared it with mice fed with a standard diet. The biometric data and the whole-body metabolic function were characterised. In addition, epididymal sperm parameters and testicular metabolic fingerprints were studied. The effect of switching from HFD to standard chow was given special attention. We integrated the data under a metabolomicsbased approach to establish a testicular metabolic profile and determine how this profile correlates with sperm quality, in animals fed with HFD and $\mathrm{HFD}_{\mathrm{t}}$.

\section{Materials and methods}

\section{Animal model}

Mus musculus C57BL6/J mice $(n=36)$ were randomly divided into three groups after weaning (21-23 days): control (CTRL) $(n=12)$, HFD $(n=12)$ and transient HFD $\left(\operatorname{HFD}_{t}\right)(n=12)$. All mice were generated from normoponderal males and females, and they were subjected to the same random in utero stimuli. Mice from the CTRL group were fed with a standard chow (\#F4031, BioServ, USA -carbohydrate: $61.6 \%$, protein: $20.5 \%$, fat: $7.2 \%$ ). Mice from the HFD group received a fat-enriched diet (\#F3282, BioServ -carbohydrate: $35.7 \%$, protein: $20.5 \%$, fat: $36.0 \%$ ) during 200 days after weaning. The mice from $\mathrm{HFD}_{\mathrm{t}}$ group were fed with a transient highfat diet (\#F3282, BioServ) for 60 days after weaning, then switched to standard chow (\#F4031, BioServ). At 120 days post weaning, mice were randomly assigned to a normoponderal female, in mating pairs, $6 \mathrm{~h}$ per day, for seven consecutive days, for breeding. Reproductive success rate, litter size and male ratio were assessed. Animals were killed by cervical dislocation 200 days after weaning, and tissues were collected for further analysis. Total body weight, water and food intake were monitored weekly from weaning to sacrifice. The animal model is compliant with the ARRIVE guidelines and was licensed by the Portuguese Veterinarian and Food Department (0421/000/000/2016).

\section{Glucose tolerance test and insulin resistance test}

One week before killing (190-193 days after weaning), animals were subjected to intraperitoneal glucose tolerance test (ipGTT) and intraperitoneal insulin tolerance test (ipITT) as described by the NIH Mouse Metabolic Phenotyping Center (MMPC) Consortium guidelines (Ayala et al. 2010).
Briefly, 16-18h before the test, access to food was removed from the animals (overnight fasting). For the ipGTT, an intraperitoneal injection with $6 \mathrm{~mL}$ glucose $30 \%$ (w/v) per $\mathrm{kg}$ of body weight was given to each animal and blood glucose levels were measured every $30 \mathrm{~min}$ during $2 \mathrm{~h}$. For the ipITT, an intraperitoneal insulin injection $(0.75 \mathrm{U}$ per $\mathrm{kg}$ body weight) was given to each animal (McGuinness et al. 2009) and blood glucose levels were measured every $30 \mathrm{~min}$ during $2 \mathrm{~h}$.

\section{Evaluation of epididymal sperm parameters}

Epididymis were isolated and placed in pre-warmed $\left(37^{\circ} \mathrm{C}\right)$ Hank's Balanced Salt Solution (HBSS) pH 7.4, minced with a scalpel blade and the suspension was incubated for $5 \mathrm{~min}$ $\left(37^{\circ} \mathrm{C}\right)$. Sperm parameters were evaluated as previously described (Rato et al. 2013).

\section{NMR spectroscopy}

A combined extraction of polar and nonpolar metabolites from testicular tissue was performed as previously described (Alves et al. 2011). The aqueous phase containing polar water-soluble metabolites was lyophilised and analysed by NMR spectroscopy as described (Jarak et al. 2018). Metabolites were identified by comparing recorded spectra with reference spectra and the Human Metabolome Database (HMDB) (Wishart et al. 2007) and according to Metabolomics Standards Initiative (MSI) guidelines for metabolite identification (Sumner et al. 2007). Identification levels are indicated in Supplementary Table 1 (see section on supplementary data given at the end of this article). After processing, ${ }^{1} \mathrm{H}$ spectra were processed using previously described methods (Jarak et al. 2018). Obtained areas were normalised by total spectral area and analysed by multivariate and univariate analysis.

\section{Metabolomics integration}

Metabolites found to have differences between groups, or to have strong and significant correlations against tested parameters, were selected for metabolomics integration using MetaboAnalyst 4.0 tools (Chong et al. 2018). Pathway enrichment and topology analysis were used for metabolic pathway identification and evaluation of metabolic impact and significance. For Pathway Topology Analysis, we used the SMPDB Mus Musculus database, relative-betweenness centrality and Fisher's exact test. Pathways with Pathway Impact $(\mathrm{PI})>0.1$ and one-tailed unadjusted $P<0.05$ were considered affected.

\section{Statistical and correlation analysis}

Different statistical methods were applied depending on the objective and the nature of data under analysis. One-way ANOVA with Tukey's post hoc test was used to compare biometric data, glucose metabolism and reproductive data between experimental groups. Normalised areas of testicular metabolite signals were also analysed by ordinary one-way ANOVA followed by Tukey's multiple comparisons test. Two-way ANOVA with Tukey's post hoc test was used to 
compare body weight, ipGTT and ipITT. Mixed factorial ANOVA with Tukey's post hoc test was applied to compare sperm morphology, in respect to within-subject variance of the counts. Multivariate analysis based on Spearman's rank correlation (Spearman's $r$ ) was used to correlate the different sets of variables in study (testicular metabolite content, sperm parameters, global metabolic state and biometric data). The correlation strength was classified according to ranks (Taylor 1990). Exact $P$ value was calculated when 16 or less pairs were correlated. An approximate $P$ value was obtained when more than 16 pairs were correlated. All methods were performed using GraphPad Prism 7.04 for Windows (GraphPad Software). Independently of the statistical method used, significance was considered whenever $P<0.05$.

\section{Results}

\section{Dietary switch from HFD to standard chow normalises biometric data and whole-body metabolic function}

Body weight was monitored throughout the experiment (Fig. 1A). Mice from CTRL group were the heaviest after weaning (CTRL: $13.09 \pm 1.31 \mathrm{~g}$; HFD: $6.64 \pm 0.23 \mathrm{~g}$; $\mathrm{HFD}_{\mathrm{t}}: 7.38 \pm 0.29 \mathrm{~g}$ ), but that difference faded in 7 days. By the 35th day after weaning, mice from the $\mathrm{HFD}$ and $\mathrm{HFD}_{\mathrm{t}}$ groups were heavier than mice from the CTRL group (CTRL: $23 \pm 0.7 \mathrm{~g}$; HFD: $24 \pm 0.6 \mathrm{~g}$; HFD;:
$26 \pm 1.0 \mathrm{~g})$. This difference increased up to 60 days after weaning, when mice fed with HFD and $\mathrm{HFD}_{\mathrm{t}}$ weighed, approximately, 20\% more than CTRL mice. At this time point, HFD in mice from the HFD group was replaced by standard chow. Fourteen days later, HFDt mice had lost weight and reached the mean values of mice from the control (CTRL: $27 \pm 0.5 \mathrm{~g}$; HFD: $28 \pm 0.9 \mathrm{~g}$ ), while mice fed with the HFD continued to gain weight $(34 \pm 1 \mathrm{~g})$. During killing, HFD mice were $50 \%$ heavier than CTRL and $\mathrm{HFD}_{\mathrm{t}}$ mice.

Gonadosomatic index (GSI) (Fig. 1B) was determined as the relative size of gonads to total body mass. Similarly, body fat (Fig. 1C) was calculated as the ratio of adipose tissue to total body weight. GSI of mice fed with a HFD was lower than that in mice from CTRL and HFD group. Weight gain as WAT is the main source for body weight increase and lower GSI in HFD (Supplementary Table 2). Liver was $20 \%$ heavier in mice fed with HFD $(1.4 \pm 0.09 \mathrm{~g})$ than in CTRL mice $(1.2 \pm 0.02 \mathrm{~g})$ and $27 \%$ heavier than in mice from the HFDt group $(1.1 \pm 0.03 \mathrm{~g})$. Finally, mice fed with a HFD presented higher glycaemia levels during ipGTT (Fig. 1D), during ipITT (Fig. 1E) and after overnight fast (CTRL: $95 \pm 2 \mathrm{mg} / \mathrm{dL}$; HFD: $116 \pm 4 \mathrm{mg} / \mathrm{dL} ; H_{F}: 85 \pm 3 \mathrm{mg} / \mathrm{dL}$ ) (Fig. $1 \mathrm{~F}$ ). $\mathrm{HFD}_{\mathrm{t}}$ mice showed fasting glycaemia levels in line with CTRL group.
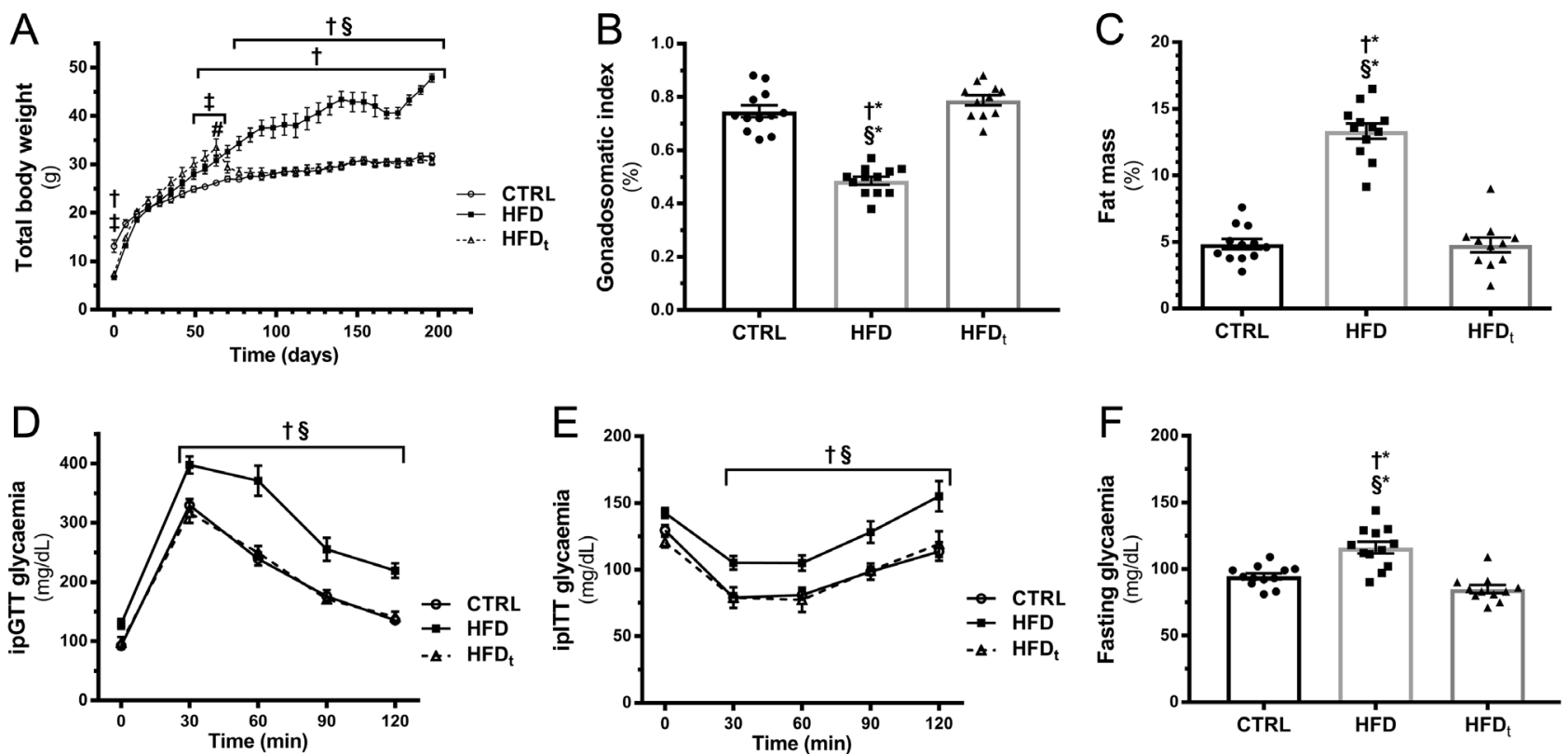

Figure 1 Biometric and metabolic characterisation of mice in this experiment, per group. Results are expressed as mean \pm S.E.M. $(n=12$ for each group). (A) Total body weight (g) evolution throughout the experiment (days). Weight was evaluated individually every 7 days. Results were tested by a repeated-measures (RM) two-way ANOVA with Tukey's multicomparison test. (B and C) Show the comparison of Gonadosomatic Index (GSI) and fat mass mean between experimental groups, respectively. Results are expressed as the mean (\%) \pm S.E.M $(n=12$ for each group). Results were tested by one-way ANOVA with Tukey's multicomparison test. Mice glycaemia $(\mathrm{mg} / \mathrm{dL})$ during the ipGTT - intraperitoneal glucose tolerance test (D) and ipITT - intraperitoneal insulin tolerance test (E). Results for ipGTT and ipITT were tested by RM two-way ANOVA with Tukey's multicomparison test. Data for fasting glucose before sacrifice $(\mathrm{F})$ was compared using ordinary one-way ANOVA with Tukey's multicomparison test. ${ }^{*}$ Dietary switch; ${ }^{+} \mathrm{CTRL}$ vs HFD; ${ }^{\ddagger} \mathrm{CTRL}$ vs HFDt; ${ }^{\$}$ HFD vs HFDt. ${ }^{*} P<0.05 ; * * P<0.005 ;{ }^{* * *} P<0.0005 ;{ }^{* * * *} P<0.0001$. 

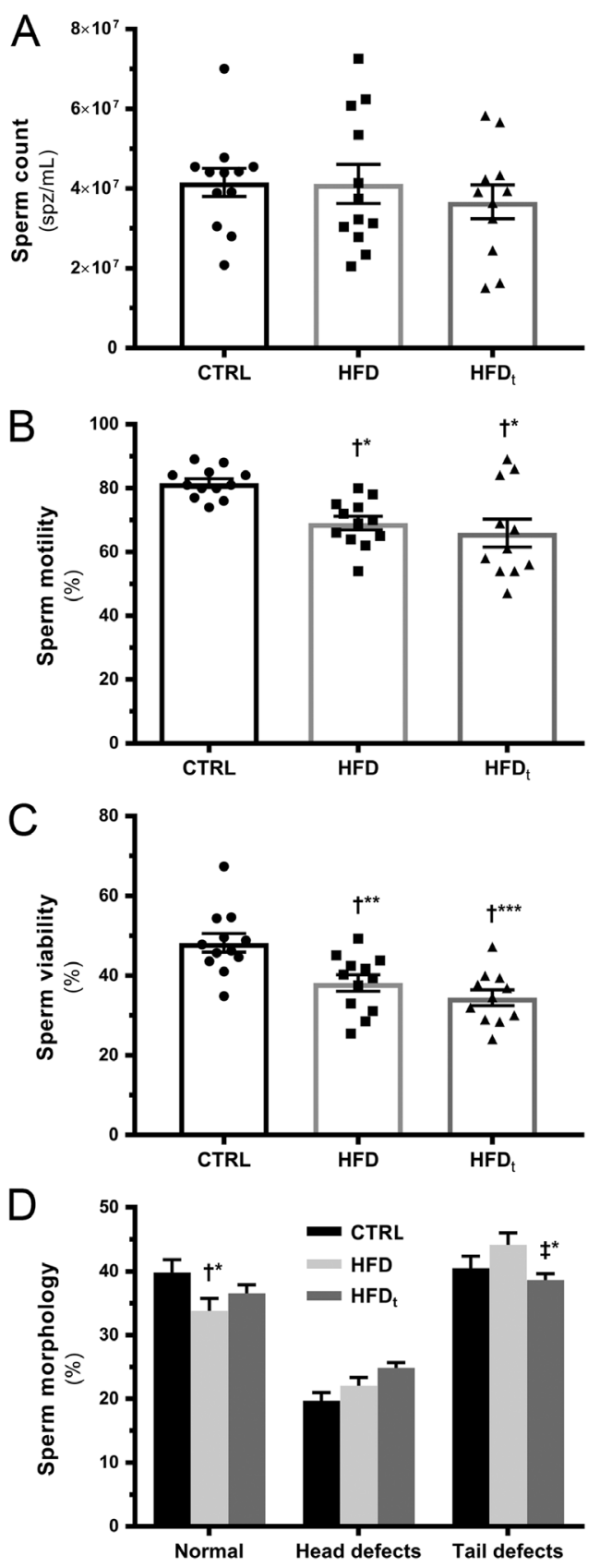

Figure 2 Characterisation of mice sperm parameters. Samples were directly obtained from mice epididymis. Results are expressed as the mean \pm S.E.M. ( $n=12$ for each group). Mice sperm concentration (A) and sperm motility (B) were assessed immediately after sample collection. Sperm viability (C) was evaluated in eosin-negrosin dyed smear, while sperm morphology (D) was classified in smears dyed with Diff-Kwik. Sperm morphology was grouped in three categories: normal, head defects (decapitated, pin head, flattened head), and tail defects (bent neck, coiled tail). Samples with more than 30\% decapitated sperm were not considered. The means for sperm counts, motility and viability were tested by one-way ANOVA with Tukey's multicomparison test. The means for sperm morphology classes were tested by mixed factorial ANOVA with Tukey's multicomparison test. Statistical significance was considered when $P \leq 0.05$. Significance marks stand as it follows: ${ }^{+}$vs CTRL; ${ }^{\ddagger}$ vs HFD; ${ }^{\S}$ vs HFD $.{ }^{*} P<0.05$; ${ }^{* *} P<0.005$; ${ }^{* * *} P<0.0005 ;{ }^{* * * *} P<0.0001$.

\section{Diet switch in mice does not restore the decreased sperm quality induced by consumption of a HFD}

We collected sperm from mice epididymis immediately after killing and characterised sperm quality by analysing sperm count, viability, motility and morphology. We found no differences in sperm count in mice from the different groups (Fig. 2A). However, mice fed with a HFD, even transiently, had approximately 12 and $15 \%$ less motile spermatozoa than mice from the control group (CTRL: $82 \pm 1 \%$; HFD: $69 \pm 2 \%$; HFD : $66 \pm 4 \%$ ) (Fig. 2B). We have observed the same tendency in sperm viability. Mice from the HFD and HFD groups presented one-fifth less viable spermatozoa than mice from the control group (CTRL: $48 \pm 2 \%$; HFD: $38 \pm 2 \%$; HFD: $35 \pm 2 \%$ ) (Fig. 2C). Concerning sperm morphology, smears from mice of the CTRL group displayed $6 \%$ more normal spermatozoa $(40 \pm 2 \%)$ than mice fed with a HFD $(34 \pm 2 \%)$, while those mice had $6 \%$ more $(44 \pm 2 \%)$ spermatozoa with tail defects than mice fed with $\mathrm{HFD}_{\mathrm{t}}(39 \pm 1 \%)$ (Fig. 2D). In addition, the animals from the HFDt group revealed the highest percentage of spermatozoa with head defects $(25 \pm 1 \%)$. Nevertheless, no changes were observed on any of the accessed reproductive parameters (reproductive success ratio, litter size and male ratio) (data not shown).

\section{Diet switch in mice did not restore energy metabolism homeostasis in the testis}

Overall, metabolome analysis revealed a unique metabolic signature for each group in mice testes. Regarding the content of metabolites related to energyproducing metabolic pathways, it revealed evident differences between CTRL and groups fed with HFD (Fig. 3). The AMP content in testes of mice from HFD and $\mathrm{HFD}_{t}$ groups was increased four-fold and three-fold respectively, when compared to the levels detected in the testis of CTRL mice (CTRL: $4.7 \times 10^{-4} \pm 8.5 \times 10^{-5}$ a.u.; HFD: $2.0 \times 10^{-3} \pm 1.9 \times 10^{-4}$ a.u.; $\mathrm{HFD}_{\mathrm{t}}: 1.4 \times 10^{-3} \pm 3.6 \times 10^{-4}$ a.u.) (Fig. 3A). Conversely, adenosine levels decreased by 30 and $20 \%$ in testes of mice from HFD and HFD (CTRL: $^{-}$ $2.3 \times 10^{-3} \pm 1.9 \times 10^{-4}$ a.u.; HFD: $1.6 \times 10^{-3} \pm 9.6 \times 10^{-5}$ a.u.; HFD $_{\mathrm{t}}: 1.8 \times 10^{-3} \pm 2.7 \times 10^{-4}$ a.u.) (Fig. $\left.3 \mathrm{~B}\right)$. Notably, the levels of lactate were not affected by diet regime (Fig. $3 \mathrm{C})$, whereas acetate levels were $50 \%$ higher in the testis of mice from the CTRL group $\left(2.3 \times 10^{-3} \pm 7.3 \times 10^{-5}\right.$ a.u. $)$ than in those from mice of the HFD $\left(1.6 \times 10^{-3} \pm 8.5 \times 10^{-5}\right.$ a.u.) and $\mathrm{HFD}_{\mathrm{t}}\left(1.5 \times 10^{-3} \pm 5.5 \times 10^{-5}\right.$ a.u.) groups (Fig. $3 \mathrm{D})$. Regarding succinate, the content in testes of mice from the $\mathrm{HFD}_{\mathrm{t}}\left(8.0 \times 10^{-3} \pm 1.9 \times 10^{-3}\right.$ a.u. $)$ was more than two-fold higher than that in testes of mice from the CTRL group $\left(3.3 \times 10^{-3} \pm 4.6 \times 10^{-4}\right.$ a.u. $)$, and more than three-fold the value obtained in testes of mice from the HFD group $\left(2.4 \times 10^{-3} \pm 4.6 \times 10^{-4}\right.$ a.u.) (Fig. 3E). Creatine remained unchanged in testes of mice from the different experimental groups (Fig. 3F). 

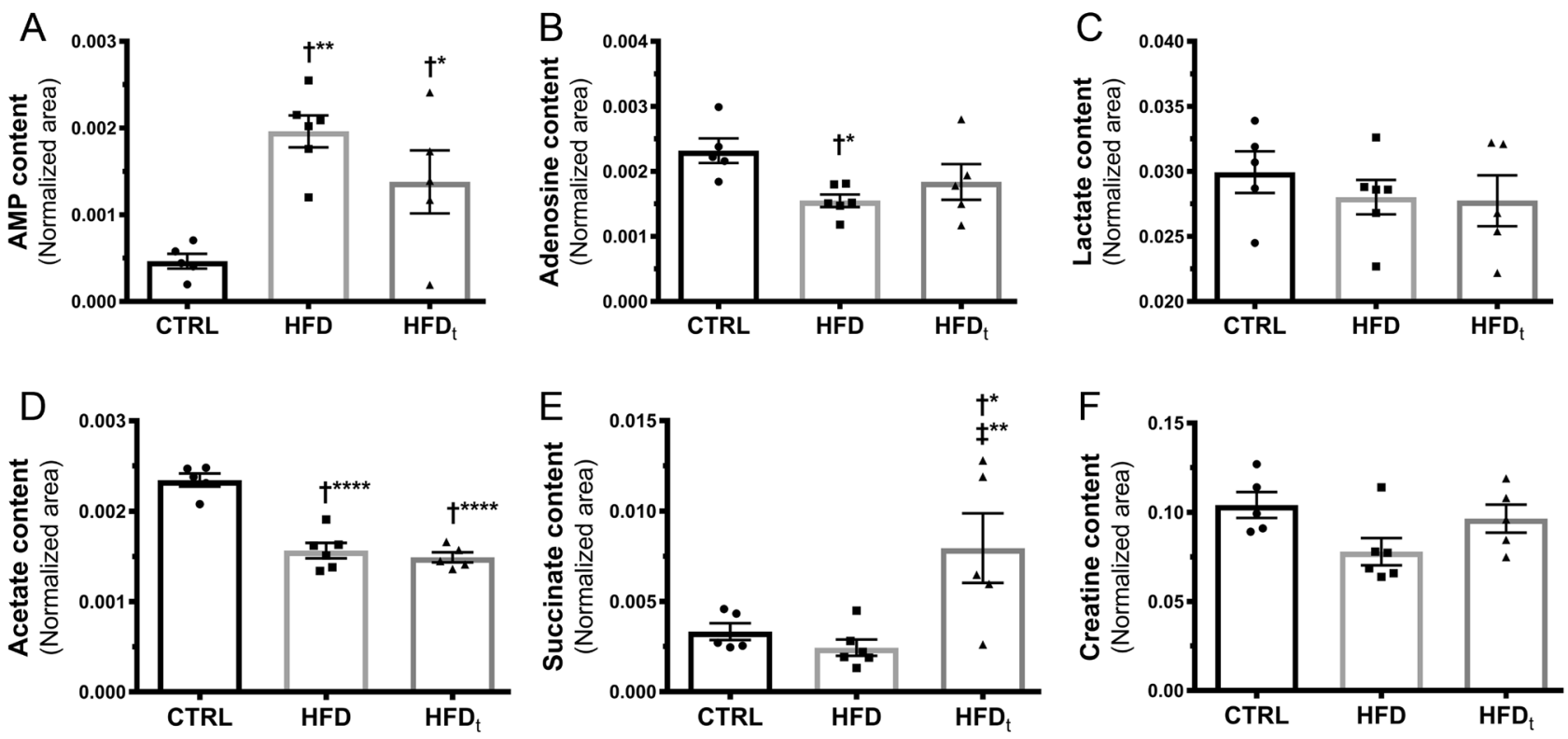

Figure $3{ }^{1} \mathrm{H}-\mathrm{NMR}$ quantification of testicular metabolites related to energy-obtaining pathways. Absolute quantification of (A) AMP, (B) adenosine, (C) lactate, (D) acetate, (E) succinate and (F) creatine, metabolites involved metabolic processes related to energy obtaining, using ${ }^{1} \mathrm{H}$-NMR. Results are expressed as mean \pm S.E.M. ( $n=6$ for each condition). Results were tested by one-way ANOVA with Tukey's multicomparison and were considered significant when $P<0.05 .{ }^{+}$vs $\mathrm{CTRL} ;{ }^{\ddagger}$ vs HFD; ${ }^{\S}$ vs $\mathrm{HFD}_{\mathrm{t}} \cdot{ }^{*} P<0.05 ;{ }^{* *} P<0.005 ;{ }^{* * *} P<0.0005 ;{ }^{* * * *} P<0.0001$.

\section{Mice testicular content of amino acids remained altered even after diet switch}

Testicular levels of six amino acids were analysed: three intermediaries of the alanine shuttle (alanine, glutamate and glutamine) and three branched chain amino acids (BCAAs) (valine, leucine and isoleucine). No differences were found in the testicular content of alanine (Fig. 4A). Glutamate was increased in testis of mice from the HFD group (Fig. 4B), while testicular glutamine levels were higher in mice from the HFD and HFD groups (Fig. 4C). Testes from mice fed with $\mathrm{HFD}_{\mathrm{t}}$ were $10 \%$ richer in glutamate $\left(1.6 \times 10^{-2} \pm 2.7 \times 10^{-4}\right.$ a.u. $)$ than testes of mice from other groups (CTRL: $1.5 \times 10^{-2} \pm 4.4 \times 10^{-4}$ a.u.;
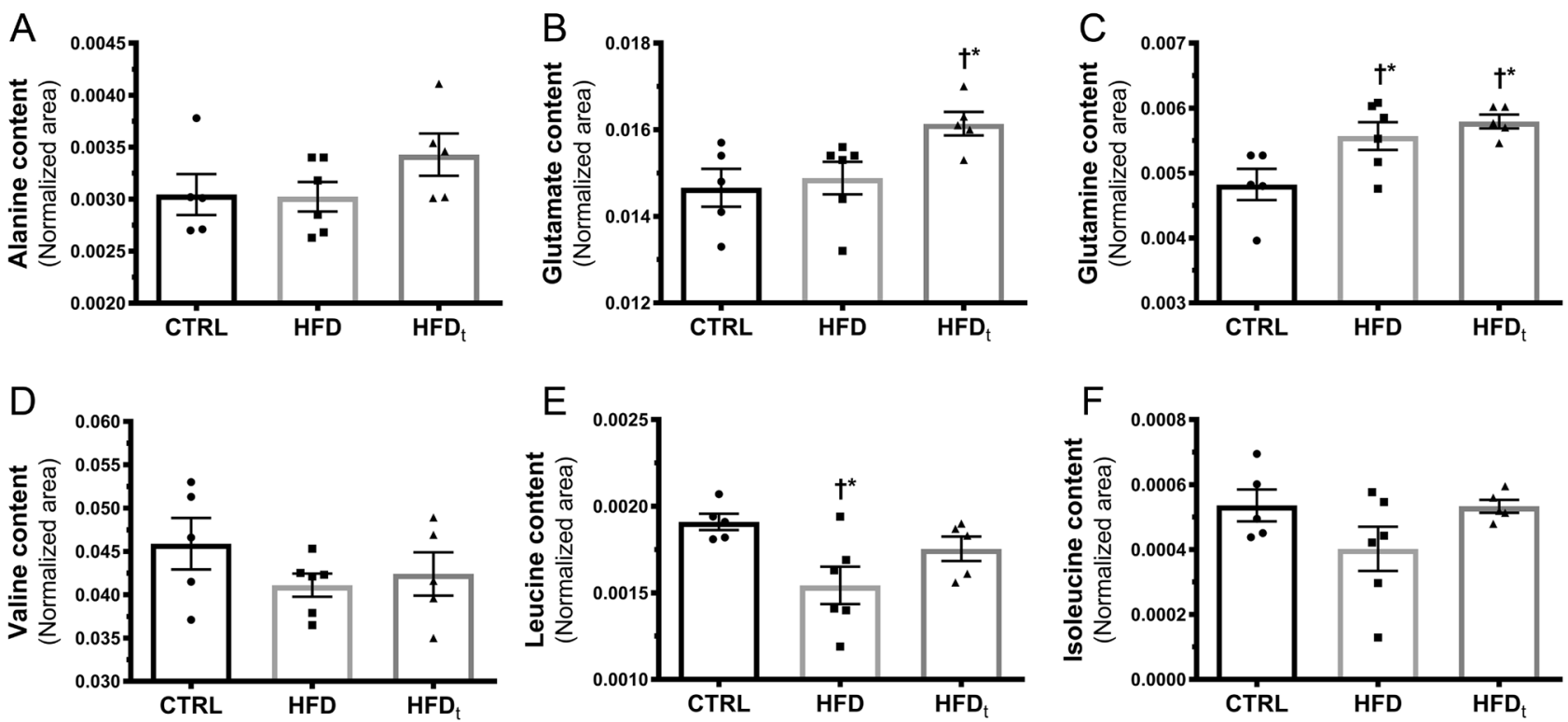

Figure $4{ }^{1} \mathrm{H}-\mathrm{NMR}$ quantification of testicular AAs. Absolute quantification of testicular content of the amino acids (A) alanine, (B) glutamate, (C) glutamine, (D) valine, (E) leucine and (F) isoleucine, using $1 \mathrm{H}-\mathrm{NMR}$. Results are expressed as mean \pm S.E.M. ( $n=6$ for each condition). Results were tested by one-way ANOVA with Tukey's multicomparison, and were considered significant when $P<0.05 .{ }^{+} \mathrm{vs}_{\mathrm{CTRL}}{ }^{\ddagger} \mathrm{Vs} \mathrm{HFD} ;{ }^{\S} \mathrm{vs} \mathrm{HFD}$. ${ }^{*} P<0.05$; ${ }^{* * P}<0.005 ;{ }^{* * *} P<0.0005$; ${ }^{* * * *} P<0.0001$. 
HFD: $1.5 \times 10^{-2} \pm 3.8 \times 10^{-4}$ a.u.). The testicular content of glutamine in mice from HFD and $\mathrm{HFD}_{\mathrm{t}}$ groups was respectively $15\left(5.6 \times 10^{-3} \pm 2.1 \times 10^{-4}\right.$ a.u. $)$ and $20 \%$ $\left(5.8 \times 10^{-3} \pm 1.1 \times 10^{-4}\right.$ a.u. $)$ greater than those from the CTRL group $\left(4.8 \times 10^{-3} \pm 2.4 \times 10^{-4}\right.$ a.u.). Concerning BCAAs, valine (Fig. 4D), leucine (Fig. 4E) and isoleucine (Fig. 4F), we have only observed alterations in the testicular content of leucine. Its levels were 19\% lower in testes of mice fed with HFD $\left(1.5 \times 10^{-3} \pm 1.1 \times 10^{-4}\right.$ a.u.) and $8 \%$ lower in testes of mice fed with $\mathrm{HFD}_{\mathrm{t}}$ $\left(1.8 \times 10^{-3} \pm 7.0 \times 10^{-5}\right.$ a.u. $)$ than in testes of mice from CTRL group $\left(1.9 \times 10^{-3} \pm 4.7 \times 10^{-5}\right.$ a.u. $)$.

\section{Diet switch in mice was not able to restore the oxidative profile in testis}

Changes were also observed in the testicular levels of metabolites related to antioxidative defence, in a diet-specific manner (Fig. 5). Our results showed that betaine increased approximately by $20 \%$ in testis of mice fed with HFD $\left(9.5 \times 10^{-2} \pm 3.0 \times 10^{-3}\right.$ a.u. $)$, comparing to the levels detected in the testis of CTRL mice $\left(7.9 \times 10^{-2} \pm 4.7 \times 10^{-3}\right.$ a.u. $)$ and mice fed with $\mathrm{HFD}_{\mathrm{t}}$ $\left(8.2 \times 10^{-2} \pm 3.2 \times 10^{-3}\right.$ a.u. $)$ (Fig. 5A). No differences were found in testicular content of taurine (Fig. 5B). Glutathione, the key cellular antioxidative component in mammals, was $60 \%$ more abundant in testes from both mice fed with HFD $\left(3.7 \times 10^{-3} \pm 2.8 \times 10^{-4}\right.$ a.u. $)$ and $\mathrm{HFD}_{\mathrm{t}}\left(3.7 \times 10^{-3} \pm 2.4 \times 10^{-4}\right.$ a.u. $)$, comparing to CTRL mice $\left(2.3 \times 10^{-3} \pm 4.76 \times 10^{-4}\right.$ a.u. $)$, suggesting increased oxidative stress (Fig. 5C). However, unlike betaine, testicular glutathione levels were not restored by diet switch.

\section{Testicular metabolic profile is associated with glucose (in)tolerance and sperm quality}

Individual values for biometric data, glucose homeostasis, sperm parameters and testicular metabolites were mutually correlated (Supplementary Tables 3, 4, 5, 6, 7, 8,9 and 10). A strong correlation was found between total body weight and fat mass $(r=0.8209, P<0.0001)$, and individual fat depots; epididymal fat $(r=0.8793$, $P<0.0001)$, perirenal fat $(r=0.8959, \quad P<0.0001)$ and retroperitoneal fat $(r=0.7695, P<0.0001)$. (Supplementary Table 3). Strong correlation was observed between total body and liver weight $(r=0.7015, P<0.0001)$. WAT weight and fat mass establish positive correlations with AUC in ipGTT and ipITT (Supplementary Table 4). WAT weight correlates with sperm defects and notably, retroperitoneal fat was correlated with pin head spermatozoa (a type of head defect) $(r=0.4338, P<0.05)$ (Supplementary Table 5). Insulin resistance is a risk factor towards abnormal spermatozoa $(r=-0.5029, P<0.005)$ (Supplementary Table 6). Overall, WAT was associated with a decrease in leucine, isoleucine and succinate, while BAT negatively correlates
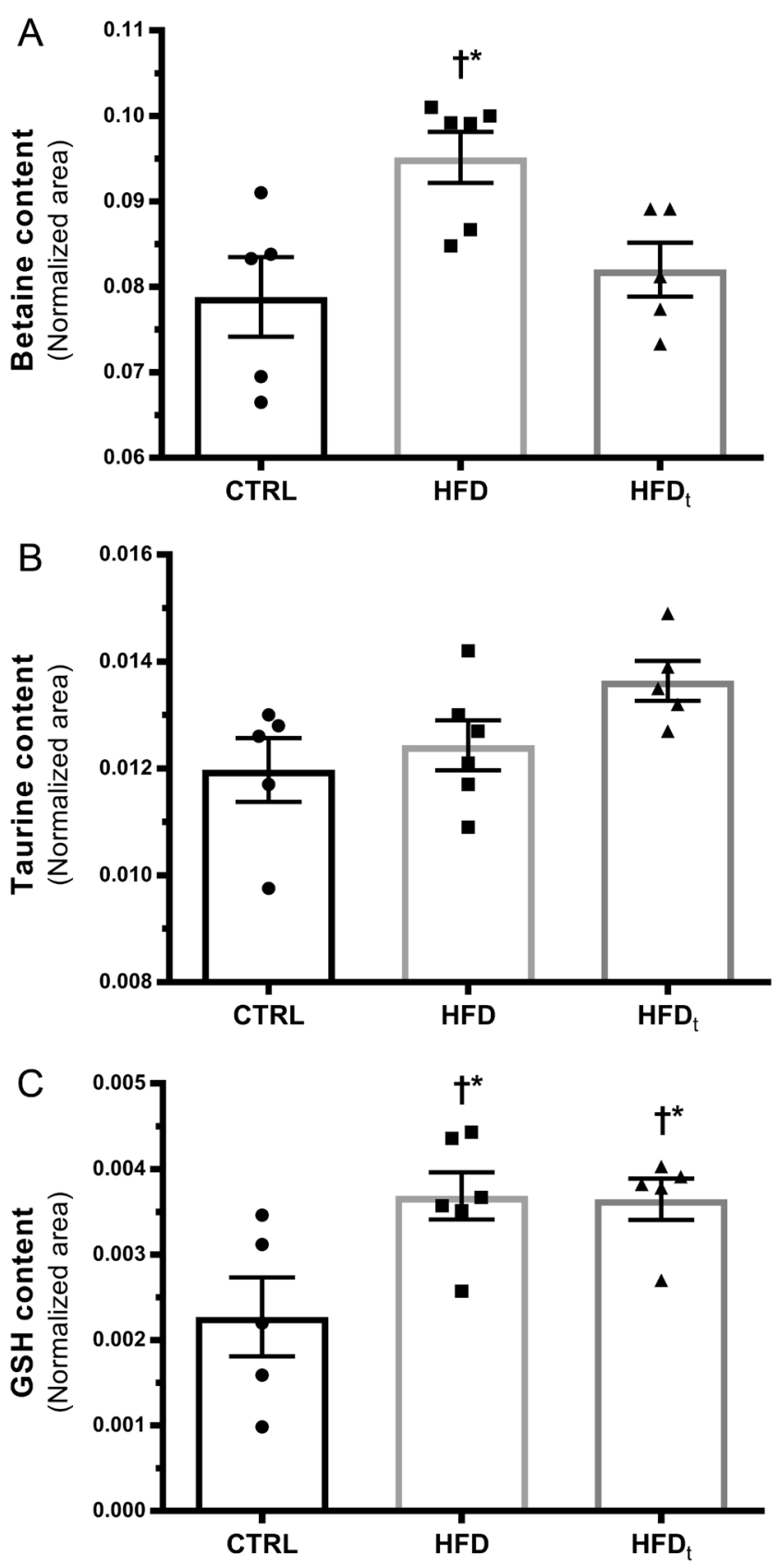

Figure $5{ }^{1} \mathrm{H}-\mathrm{NMR}$ quantification of testicular antioxidants. Absolute quantification of (A) betaine, (B) taurine and (C) glutathione, metabolites involved in the antioxidative action, using ${ }^{1} \mathrm{H}-\mathrm{NMR}$. Results are expressed as mean \pm S.E.M. ( $n=6$ for each condition). Results were tested by one-way ANOVA with Tukey's multicomparison and were considered significant when $P<0.05 .{ }^{+} \mathrm{vs}$ CTRL; ${ }^{\ddagger}$ vs HFD; ${ }^{\S}$ vs HFD H $^{*} P<0.05 ;{ }^{* *} P<0.005 ;{ }^{* * *} P<0.0005$; $* * * * P<0.0001$.

with isoleucine $(r=-0.117, \quad P<0.05)$ (Supplementary Table 7). Total body weight showed a very strong positive correlation with taurine $(r=-0.8194, P<0.0005)$, whereas taurine was negatively correlated to testis weight. Glucose intolerance is correlated with betaine $(r=0.5180, P<0.05)$, 

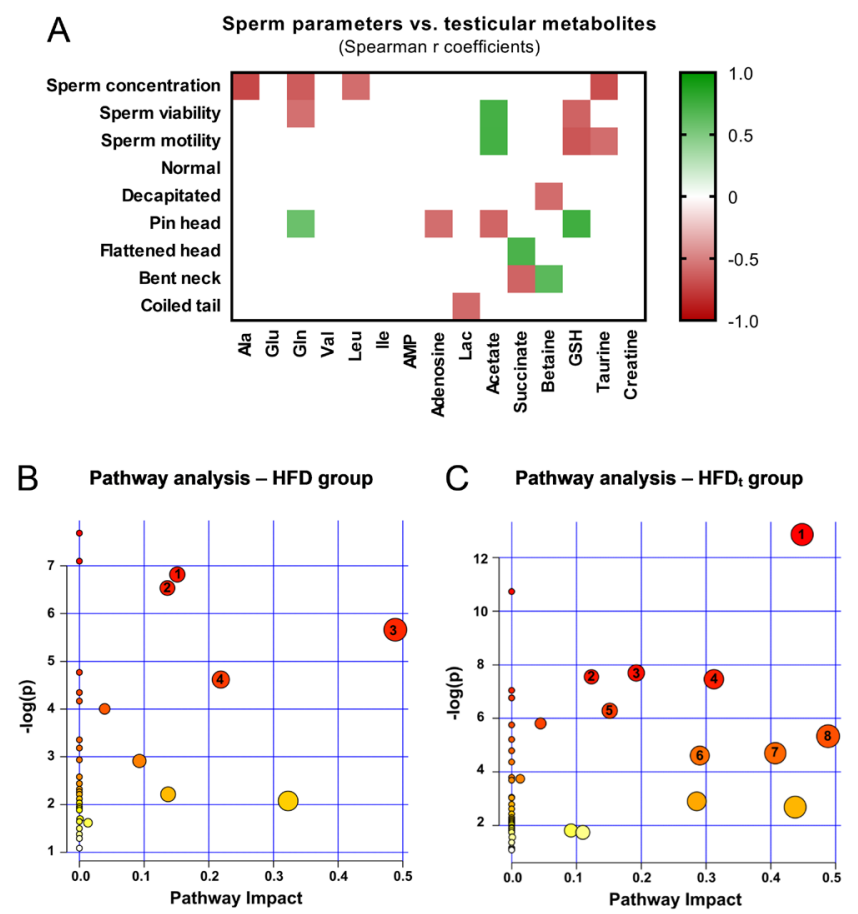

Figure 6 Metabolomics integration of NMR data. Summary of main metabolomic correlations drawn from our experimental model in testis. (A) Simplified correlation matrix of sperm parameters vs testicular metabolites. The scale represents Spearman $r$ coefficient values, when $P<0.05$ ( $n=16$, Exact $P$ value). (B) MetaboAnalyst 4.0 Pathway Analysis Tool was used to identify the most affected metabolic pathways in HFD mice, using the list of metabolites which presented differences from CTRL group. Hence, input metabolites were: leucine, betaine, AMP, acetate, glutamine and glutathione. 1 - pyruvate metabolism; 2 - glutamate metabolism; 3 - ethanol degradation; 4 - ammonia recycling. (C) The same methodology as used to profile the most relevant metabolic changes in HFDt group. Input metabolites were adenosine, succinate, glutamate, AMP, acetate, glutamine and glutathione. 1 - glutamate metabolism; 2 - purine metabolism; 3 - urea cycle; 4 - ammonia recycling; 5 pyruvate metabolism; 6 - cysteine metabolism; 7 - glutathione metabolism; 8 - ethanol degradation.

conversely to succinate $(r=-0.5059 ; P<0.05)$ and creatine $(r=-0.7285, \quad P<0.005) \quad$ (Supplementary Table 8). A correlation matrix illustrates the relation between testicular metabolites and sperm parameters (Fig. 6A). Amino acids were negatively correlated with sperm counts (sperm concentration) and sperm viability; for example, glutamine is positively correlated to pin head defects $(r=0.5771$, $P<0.05)$. Acetate was found to be a protective factor for sperm quality (Supplementary Table 9).

\section{Male reproductive dysfunction in mice is caused by metabolic interference of HFD}

After analysing all the individual correlations between biometric data, glucose homeostasis, sperm parameters and testicular metabolome of our experimental model, we explored how they associate with the differences observed in the first stage of our study (Fig. 6). For mice fed with HFD, four metabolic pathways were found impacted in testes (Fig. 6B). Pyruvate $(\mathrm{PI}=0.15$, $P=1.10 \times 10^{-3}, \quad F D R=3.60 \times 10^{-2}$ ) and glutamate metabolism $\left(\mathrm{PI}=0.14, P=1.46 \times 10^{-3}, \mathrm{FDR}=3.60 \times 10^{-2}\right)$ were the most significantly affected pathways in testes. Ethanol degradation $\left(\mathrm{PI}=0.49, P=3.48 \times 10^{-3}\right.$, $\left.\mathrm{FDR}=6.89 \times 10^{-2}\right)$ and ammonia recycling $(\mathrm{PI}=0.22$, $\left.P=9.87 \times 10^{-3}, \quad F D R=0.14\right)$ were also affected. The same metabolic pathways were affected in mice fed with $\mathrm{HFD}_{\mathrm{t}}$ (Fig. 6C). Glutamate metabolism was the most affected metabolic pathway $\left(\mathrm{PI}=0.45, P=2.60 \times 10^{-6}\right.$, $\left.\mathrm{FDR}=2.57 \times 10^{-4}\right)$, three-fold more impacted than in HFD group. Ammonia recycling $\left(\mathrm{PI}=0.31, P=5.75 \times 10^{-4}\right.$, FDR $=1.14 \times 10^{-2}$ ) was $40 \%$ more impacted in testes of mice fed with $\mathrm{HFD}_{\mathrm{t}}$. Pyruvate metabolism and ethanol degradation were equally impacted in testes of mice from HFD and HFD. Additionally, HFD $\mathrm{H}_{\mathrm{t}}$ mice suffered impact in testicular purine metabolism $(\mathrm{PI}=0.12$, $\left.P=5.25 \times 10^{-4}, \mathrm{FDR}=1.14 \times 10^{-2}\right)$, urea cycle $(\mathrm{PI}=0.19$, $\left.P=4.55 \times 10^{-4}, \mathrm{FDR}=1.14 \times 10^{-2}\right)$, cysteine metabolism $\left(\mathrm{PI}=0.29, \quad P=9.93 \times 10^{-3}, \quad \mathrm{FDR}=6.15 \times 10^{-2}\right) \quad$ and glutathione metabolism $\left(\mathrm{PI}=0.41, \quad P=9.10 \times 10^{-4}\right.$, $\mathrm{FDR}=6.01 \times 10^{-2}$ ).

\section{Discussion}

The obesity pandemic and the decline of sperm quality share a timeline with a common denominator: HFD (World Health Organization 2000, Skakkebaek et al. 2016). Yet, there is a gap on mechanistic studies on the subject. Clinical studies often have confounding factors. Thus, animal models can be a reliable choice to study the molecular mechanisms of HFD-induced male infertility. Herein, we used NMR-based metabolomics to identify testicular metabolic fingerprints induced by HFD and how weight loss caused by dietary switch from HFD to normal diet affects sperm quality, in a rodent model (Mus musculus). A number of metabolomics-based studies were already used to unveil the molecular mechanisms associated with male fertility (dys)function (Deepinder et al. 2007, Minai-Tehrani et al. 2016). Recently, we described ageing-associated testicular changes using NMR-based metabolomics in a rodent model (Jarak et al. 2018). In the present study, we detected distinct testicular metabolic signatures in animals fed by HFD, even if temporarily. Additionally, changes observed in testicular metabolome were correlated with general metabolic status and parameters of sperm quality.

Our group has extensively addressed the changes induced by HFD and related diseases in the male reproductive system. We have described mechanisms by which HFD induce a pre-diabetic state and cause functional changes in the testis (Rato et al. 2013). In addition, we demonstrated how energy homeostasis triggers specific metabolic shifts in Sertoli cells 
(Martins et al. 2015, 2016, 2019, Jesus et al. 2016). We further discussed how excess accumulation of lipids due to obesogenic substances impairs sperm maturation (Rato et al. 2017). Besides, deleterious effects associated with pathological states in energy homeostasis impair endocrine function and metabolic balance in testis, which can cause abnormal sperm parameters (Rato et al. 2014, 2015, Alves et al. 2015), suggesting functional changes in testicular cells beyond the somatic SCs. In the present work, we add a new level of evidence, based on Multivariate Analysis and Metabolomics, to show that the metabolic fingerprints induced by HFD in testes may not be fully reverted by dietary switch.

Poorer sperm quality was found in mice fed with a HFD. Interestingly, even though mice from the HFD group were fed with a balanced diet for the majority of their lives, some metabolic changes and defects in sperm quality caused by HFD and/or previous obesity were not reversed by dietary change/weight loss. The period that mice from the HFD ${ }_{t}$ group were fed with a HFD (60 days) overlaps with childhood, puberty and the early years of adulthood, a critical age for male reproductive maturation (Dutta \& Sengupta 2016). The first two spermatogenic cycles in mice occur during this period (Whittingham \& Wood 1983), stressing the importance of testicular environment in this phase for successful reproductive outcomes later in life (Woodruff et al. 2008). This fact is even more interesting considering that diet switch and weight loss were effective in recovering mice weight to normal level and in preventing the onset of metabolic syndrome. In Mus musculus, a spermatogenic cycle takes approximately 9 days, while spermatogenesis takes 40 days (Costa et al. 2018). Therefore, in mice from the $\mathrm{HFD}_{\text {t }}$ group, the time between diet reversion and killing allows the completion of 11 spermatogenic cycles, which are enough to correctly assess the impact of the new diet in sperm parameters. Nevertheless, it is interesting that sperm parameters did not lead to poorer reproductive outcomes. No differences were found in pregnancy success rates, litter size or male ratio, though litter size was smaller than officially reported in this strain (Murray et al. 2010).

Our data show that WAT is the main source for body weight differences observed between groups. Besides, the differences detected in liver weight underline the role of this organ in mediating the effects induced by HFD. We found a very strong positive correlation between WAT and liver weight, particularly in HFD mice. This correlation has been widely described and reflects steatosis caused by diet (Samuel et al. 2004, Fraulob et al. 2010, Gao et al. 2015, Lai et al. 2015), a condition that may progress to non-alcoholic fatty liver disease (NAFLD) and ultimately to cirrhosis. In addition, WAT accumulation and liver enlargement (steatosis) are predictive factors for metabolic dysfunction, towards metabolic disease (Dixon et al. 2001, Kotronen \& YkiJarvinen 2008). We found poorer performance of mice fed with HFD during ipGTT and ipITT, which reflect metabolic syndrome onset. In fact, WAT deposits are extremely correlated with poorer performance in ipGTT and ipITT and can be regarded as the link between HFD and the onset of metabolic disease (Rato et al. 2013).

Testicular metabolome and evaluated sperm parameters were distinct in HFD and $\mathrm{HFD}_{\mathrm{t}}$ groups, although globally negatively affected by HFD. In both groups, testicular metabolome was enriched in AMP, glutamine and glutathione, whereas acetate content was strikingly reduced. In addition, nucleic acid metabolism was significantly affected by HFD. AMP participates in energy production homeostasis, which is indispensable in highly metabolically active tissue. AMP is involved in the regulation of lipolysis and lipogenesis in response to insulin; thus, it is a marker for whole-body metabolic homeostasis (Hajer et al. 2008). The increase in AMP content was correlated with the weight of BAT, WAT and liver, but not total body weight. Also, AMP is involved in spermatogenesis through cAMP activated signalling pathways (AMPK). AMPK signalling is an important regulator of the nutritional support of spermatogenesis by regulating Sertoli cell metabolism (Galardo et al. 2007), thus highlighting the relevance of these signalling pathways and how they respond to fat in the testicular tissue. However, the metabolic hallmarks observed, as glucose intolerance, are mostly correlated with epididymal fat, which humans lack (Wronska \& Kmiec 2012). Thus, caution should be taken when discussing these effects in humans. Yet, the model was able to correlate retroperitoneal fat weight with the prevalence of head and tail defects in sperm of mice (Chen et al. 2013, McPherson \& Lane 2015), which was already reported in humans (Martini et al. 2010, Rato et al. 2017).

Concerning testicular metabolome, we found that glutamine and acetate were correlated with sperm quality. Glutamine is an important energetic substrate for the somatic Sertoli cells (Oliveira et al. 2015). Hence, testicular accumulation of glutamine may indicate SC metabolic dysfunction. On the other hand, acetate, an energy substrate obtained from lipolysis (Martins et al. 2015), was reduced in both groups of mice fed with HFD and $\mathrm{HFD}_{\mathrm{t}}$. We may hypothesise that acetate is being redirected for membrane remodelling, possibly due to increased cell turnover in testes (Alves et al. 2012). This assumption is supported by the changes found in antioxidant intermediaries and in purine metabolism. On the other hand, acetate excretion by SC may be inhibited by the effect of leptin (Martins et al. 2015). Glutathione content was upregulated in testes of mice from both HFD groups, while betaine content was only increased in those fed with HFD. Diet switch failed to attenuate oxidative stress as evidenced by the increased levels of glutathione. High levels of glutathione in testes of HFD-fed mice were associated with higher prevalence of sperm pin head defects, lower sperm viability and decreased sperm motility. 
The consumption of HFD is associated with local inflammatory process in mice testes (Chen et al. 2013), which leads to glutathione overexpression. Recalling data obtained on testicular acetate content, this increase may be related to a local membrane remodelling process, associated with germ cell turnover by SCs (Martins et al. 2015). Although we should be cautious about this claim, as no apoptotic markers in testes were assessed, this response to HFD has been previously reported (Isidori et al. 1999, Mu et al. 2017). Yet, it is possible to assume that diet, rather than fat deposition, is the major contributor to changes in sperm viability, and glutathione and acetate testicular content. All those metrics were changed in HFD groups, but did not significantly correlated with fat mass or fat deposits. Testes of mice fed with HFD were further enriched in betaine, an intermediary of antioxidant pathways that is also associated with glucose intolerance and insulin resistance (Wang et al. 2011). Indeed, we have also found a strong correlation between betaine and the AUC of ipGTT in HFD-fed mice. Testicular betaine content was also strongly correlated with weight gain of WAT pads, which may link the presence of this metabolite in testes to a direct effect of HFD. Decreased levels of testicular leucine is another hallmark of HFD. We found that leucine content in testes was negatively correlated with WAT weight. According to the metabolite correlation matrix (Supplementary Table 10), leucine is negatively correlated with AMP, which may indicate an AMPK-related signalling cascade repressing leucine excretion or leucine consumption in testes of mice fed with HFD. Although increased serum concentration of leucine has been correlated with the onset of T2DM in humans (Wang et al. 2011), we have observed an opposite effect in our study: mice fed with HFD, which displayed glucose intolerance and insulin resistance, had lower leucine levels in testes. This tissue-specific difference should not be overlooked and shows a functional specificity of the testis concerning amino acids metabolism, which should be further explored.

The most distinct metabolic feature in testes of mice fed with $\mathrm{HFD}_{\mathrm{t}}$ was the enrichment in adenosine, glutamate and succinate. Overall these three metabolites are associated with WAT lipid mobilisation, weight loss, decreased percentage of sperm with bent neck, increased percentage of sperm pin head defects and improved glucose tolerance. Succinate has been correlated with sperm defects and glucose intolerance. A strong correlation was also observed with perirenal and epididymal fat lipid mobilisation. Previous studies reported changes in gene expression of epididymal WAT in response to diet restriction, namely in energy and lipid metabolism, with particular inhibition of genes related to mitochondrial pathways (Duivenvoorde et al. 2011). The authors reported the same phenotypic changes we observed in mice fed with $\mathrm{HFD}_{\mathrm{t}}$, such as weight loss and metabolic normalisation. The accumulation of succinate in testes of mice fed with a $\mathrm{HFD}_{\mathrm{t}}$ also suggests increased TCA activity and mitochondrial involvement in the irreversible deleterious effects caused by a diet rich in fats. Although lipophagy is primarily described in adipocytes and hepatocytes, with pivotal implications in lipid homeostasis (Christian et al. 2013, Liu \& Czaja 2013), we should not overlook the possibility that a similar process occurs in testes, namely in SCs. Lipophagy allows the release of lipids from lipid droplets, which can then be recruited for metabolic functions (Liu \& Czaja 2013). This process is another energy-triggered phenomenon and HFD, obesity and hyperinsulinaemia inhibit it, prompting lipid accumulation (Christian et al. 2013, Liu \& Czaja 2013). Nevertheless, the process is triggered by cytoplasmatic concentrations of FFAs and cholesterol, rather than extracellular availability (Liu \& Czaja 2013). In fact, SCs accumulate lipid droplets as a result of phagocytosis of apoptotic germ cells (Wang et al. 2006).

Interestingly, we found that pyruvate metabolism, glutamate metabolism, ethanol degradation and ammonia recycling in testes were irreversibly affected by HFD, as the differences were verified even after dietary switch and weight loss. Furthermore, testes of mice fed with $\mathrm{HFD}_{\mathrm{t}}$ presented alterations in purine metabolism, urea cycle, cysteine metabolism and glutathione. Those alterations, associated with antioxidant defences and metabolic reprograming, are linked to testicular metabolic adaptations to diet switch, posterior to sexual maturation.

Overall, our observations have a translational echo in a recent meta-analysis by Lee et al. (2019), which concluded that there are no improvements in sperm quality after metabolic bariatric surgery, despite the improvements on overall metabolic and endocrine function. In another review, Oliveira et al. (2017) postulates that dietary interventions, such as bariatric surgery, exercise plans or caloric restriction may not present satisfactory results to male fertility due to collateral damages induced by the sudden weight loss and prospective accumulation of endogenous toxicants. Our study has, however, some limitations. We have only used polar testicular fractions to quantify metabolites, and there are dissimilarities between animal models and humans. Furthermore, our experimental model does not allow to differentiate between HFD and weight gain/obesity, because the switch from HFD to normal diet comprises dietary switch plus weight loss. Despite several sperm parameters have been affected by the consumption of HFD, we are cautious to draw conclusions regarding the reproductive success of these mice, as our protocol does not provide an extensive assessment of fertility outcomes. Nevertheless, this is the first study showing that excess of weight/obesity until early adulthood can cause irreversible damage to testicular function and sperm quality even when diet reversion restored normal global metabolic status. The 
biomarkers reported in this study are potential clinical targets for prevention and treatment of obesity-related infertility in males.

\section{Supplementary data}

This is linked to the online version of the paper at https://doi.org/10.1530/REP-19-0259.

\section{Declaration of interest}

The authors declare that there is no conflict of interest that could be perceived as prejudicing the impartiality of the research reported.

\section{Funding}

This work was supported by the Portuguese Foundation for Science and Technology (PTDC/MEC-AND/28691/2017). L Crisóstomo (SFRH/BD/128584/2017), M G Alves (IFCT2015) and P F Oliveira (IFCT2015) were funded by the Portuguese Foundation for Science and Technology; L Crisóstomo and M G Alves were also supported by the Portuguese Society of Diabetology ('Nuno Castel-Branco' grant); and M G Alves and P F Oliveira were also supported by the Amadeu Dias Foundation.

\section{Author contribution statement}

PF O, MGA and R L B contributed to study design, analysis and interpretation of data. $L R, I$ I and $L C$ performed experimental work. L C edited the images and tables, performed the statistics and contributed to analysis and interpretation of data. B M S and J F R critically reviewed the manuscript and suggested modifications. All the authors contributed to manuscript writing/editing and approved the final version.

\section{Acknowledgements}

The authors acknowledge the Portuguese Nuclear Magnetic Resonance Network (REDE/1517/RMN/2005) for access to their facilities.

\section{References}

Alves MG, Oliveira PJ \& Carvalho RA 2011 Substrate selection in hearts subjected to ischemia/reperfusion: role of cardioplegic solutions and gender. NMR in Biomedicine 24 1029-1037. (https://doi.org/10.1002/ nbm.1640)

Alves MG, Socorro S, Silva J, Barros A, Sousa M, Cavaco JE \& Oliveira PF 2012 In vitro cultured human Sertoli cells secrete high amounts of acetate that is stimulated by $17 \beta$-estradiol and suppressed by insulin deprivation. Biochimica et Biophysica Acta 1823 1389-1394. (https:// doi.org/10.1016/j.bbamcr.2012.06.002)
Alves MG, Martins AD, Moreira PI, Carvalho RA, Sousa M, Barros A, Silva J, Pinto S, Simões T \& Oliveira PF 2015 Metabolic fingerprints in testicular biopsies from type 1 diabetic patients. Cell and Tissue Research 362 431-440. (https://doi.org/10.1007/s00441-015-2217-5)

Ayala JE, Samuel VT, Morton GJ, Obici S, Croniger CM, Shulman GI, Wasserman DH, McGuinness OP \& NIH Mouse Metabolic Phenotyping Center Consortium 2010 Standard operating procedures for describing and performing metabolic tests of glucose homeostasis in mice. Disease Models and Mechanisms 3 525-534. (https://doi.org/10.1242/ dmm.006239)

Chen XL, Gong LZ \& Xu JX 2013 Antioxidative activity and protective effect of probiotics against high-fat diet-induced sperm damage in rats. Animal 7 287-292. (https://doi.org/10.1017/S1751731112001528)

Chong J, Soufan O, Li C, Caraus I, Li S, Bourque G, Wishart DS \& Xia J 2018 MetaboAnalyst 4.0: towards more transparent and integrative metabolomics analysis. Nucleic Acids Research 46 W486-W494. (https://doi.org/10.1093/nar/gky310)

Christian P, Sacco J \& Adeli K 2013 Autophagy: emerging roles in lipid homeostasis and metabolic control. Biochimica et Biophysica Acta 1831 819-824. (https://doi.org/10.1016/j.bbalip.2012.12.009)

Costa GMJ, Lacerda SMSN, Figueiredo AFA, Leal MC, Rezende-Neto JV \& França LR 2018 Higher environmental temperatures promote acceleration of spermatogenesis in vivo in mice (Mus musculus). Journal of Thermal Biology 77 14-23. (https://doi.org/10.1016/j.jtherbio.2018.07.010)

Deepinder F, Chowdary HT \& Agarwal A 2007 Role of metabolomic analysis of biomarkers in the management of male infertility. Expert Review of Molecular Diagnostics 7 351-358. (https://doi. org/10.1586/14737159.7.4.351)

Dixon JB, Bhathal PS \& O'Brien PE 2001 Nonalcoholic fatty liver disease: predictors of nonalcoholic steatohepatitis and liver fibrosis in the severely obese. Gastroenterology 121 91-100. (https://doi.org/10.1053/ gast.2001.25540)

Duivenvoorde LPM, van Schothorst EM, Bunschoten A \& Keijer J 2011 Dietary restriction of mice on a high-fat diet induces substrate efficiency and improves metabolic health. Journal of Molecular Endocrinology 47 81-97. (https://doi.org/10.1530/JME-11-0001)

Dutta S \& Sengupta P 2016 Men and mice: relating their ages. Life Sciences 152 244-248. (https://doi.org/10.1016/j.Ifs.2015.10.025)

Fraulob JC, Ogg-Diamantino R, Fernandes-Santos C, Aguila MB \& Mandarim-de-Lacerda CA 2010 A mouse model of metabolic syndrome: insulin resistance, fatty liver and non-alcoholic fatty pancreas disease (NAFPD) in C57BL/6 mice fed a high fat diet. Journal of Clinical Biochemistry and Nutrition 46 212-223. (https://doi.org/10.3164/ jcbn.09-83)

Galardo MN, Riera MF, Pellizzari EH, Cigorraga SB \& Meroni SB 2007 The AMP-activated protein kinase activator, 5-aminoimidazole-4carboxamide-1-bD-ribonucleoside, regulates lactate production in rat Sertoli cells. Journal of Molecular Endocrinology 39 279-288. (https:// doi.org/10.1677/JME-07-0054)

Gao M, Ma Y \& Liu D 2015 High-fat diet-induced adiposity, adipose inflammation, hepatic steatosis and hyperinsulinemia in outbred CD-1 mice. PLOS ONE 10 e0119784. (https://doi.org/10.1371/journal. pone.0119784)

Hajer GR, van Haeften TW \& Visseren FLJ 2008 Adipose tissue dysfunction in obesity, diabetes, and vascular diseases. European Heart Journal 29 2959-2971. (https://doi.org/10.1093/eurheartj/ehn387)

Hamilton BE \& Ventura SJ 2006 Fertility and abortion rates in the United States, 1960-2002. International Journal of Andrology 29 34-45. (https:// doi.org/10.1111/j.1365-2605.2005.00638.x)

Isidori AM, Caprio M, Strollo F, Moretti C, Frajese G, Isidori A \& Fabbri A 1999 Leptin and androgens in male obesity: evidence for leptin contribution to reduced androgen levels. Journal of Clinical Endocrinology and Metabolism 84 3673-3680. (https://doi.org/10.1210/ jcem.84.10.6082)

Jarak I, Almeida S, Carvalho RA, Sousa M, Barros A, Alves MG \& Oliveira PF 2018 Senescence and declining reproductive potential: insight into molecular mechanisms through testicular metabolomics. Biochimica et Biophysica Acta: Molecular Basis of Disease 1864 3388-3396. (https:// doi.org/10.1016/j.bbadis.2018.07.028)

Jesus TT, Oliveira PF, Silva J, Barros A, Ferreira R, Sousa M, Cheng CY, Silva BM \& Alves MG 2016 Mammalian target of rapamycin controls glucose consumption and redox balance in human Sertoli cells. 
Fertility and Sterility 105 825.e3-833.e3. (https://doi.org/10.1016/j. fertnstert.2015.11.032)

Kotronen A \& Yki-Jarvinen H 2008 Fatty liver: a novel component of the metabolic syndrome. Arteriosclerosis, Thrombosis, and Vascular Biology 28 27-38. (https://doi.org/10.1161/ATVBAHA.107.147538)

Lai YS, Chen WC, Kuo TC, Ho CT, Kuo CH, Tseng YJ, Lu KH, Lin SH, Panyod S \& Sheen LY 2015 Mass-spectrometry-based serum metabolomics of a C57BL/6] mouse model of high-fat-diet-induced non-alcoholic fatty liver disease development. Journal of Agricultural and Food Chemistry 63 7873-7884. (https://doi.org/10.1021/acs.jafc.5b02830)

Lee Y, Dang JT, Switzer N, Yu J, Tian C, Birch DW \& Karmali S 2019 Impact of bariatric surgery on male sex hormones and sperm quality: a systematic review and meta-analysis. Obesity Surgery 29 334-346. (https://doi.org/10.1007/s11695-018-3557-5)

Liu K \& Czaja MJ 2013 Regulation of lipid stores and metabolism by lipophagy. Cell Death and Differentiation 20 3-11. (https://doi. org/10.1038/cdd.2012.63)

Martini AC, Tissera A, Estofán D, Molina RI, Mangeaud A, de Cuneo MF \& Ruiz RD 2010 Overweight and seminal quality: a study of 794 patients. Fertility and Sterility 94 1739-1743. (https://doi.org/10.1016/j. fertnstert.2009.11.017)

Martins AD, Moreira AC, Sá R, Monteiro MP, Sousa M, Carvalho RA, Silva BM, Oliveira PF \& Alves MG 2015 Leptin modulates human Sertoli cells acetate production and glycolytic profile: a novel mechanism of obesity-induced male infertility? Biochimica et Biophysica Acta 1852 1824-1832. (https://doi.org/10.1016/j.bbadis.2015.06.005)

Martins AD, Sá R, Monteiro MP, Barros A, Sousa M, Carvalho RA, Silva BM, Oliveira PF \& Alves MG 2016 Ghrelin acts as energy status sensor of male reproduction by modulating Sertoli cells glycolytic metabolism and mitochondrial bioenergetics. Molecular and Cellular Endocrinology 434 199-209. (https://doi.org/10.1016/j.mce.2016.07.008)

Martins AD, Monteiro MP, Silva BM, Barros A, Sousa M, Carvalho RA, Oliveira PF \& Alves MG 2019 Metabolic dynamics of human Sertoli cells are differentially modulated by physiological and pharmacological concentrations of GLP-1. Toxicology and Applied Pharmacology 362 1-8. (https://doi.org/10.1016/j.taap.2018.10.009)

McGuinness OP, Ayala JE, Laughlin MR \& Wasserman DH 2009 NIH experiment in centralized mouse phenotyping: the Vanderbilt experience and recommendations for evaluating glucose homeostasis in the mouse. American Journal of Physiology: Endocrinology and Metabolism 297 E849-E855. (https://doi.org/10.1152/ajpendo.90996.2008)

McPherson NO \& Lane M 2015 Male obesity and subfertility, is it really about increased adiposity? Asian Journal of Andrology 17 450-458. (https://doi.org/10.4103/1008-682X.148076)

Minai-Tehrani A, Jafarzadeh N \& Gilany K 2016 Metabolomics: a state-of-the-art technology for better understanding of male infertility. Andrologia 48 609-616. (https://doi.org/10.1111/and.12496)

Mu Y, Yan WJ, Yin TL, Zhang Y, Li J \& Yang J 2017 Diet-induced obesity impairs spermatogenesis: a potential role for autophagy. Scientific Reports 7 43475. (https://doi.org/10.1038/srep43475)

Murray SA, Morgan JL, Kane C, Sharma Y, Heffner CS, Lake J \& Donahue LR 2010 Mouse gestation length is genetically determined. PLOS ONE $\mathbf{5}$ e12418. (https://doi.org/10.1371/journal.pone.0012418)

Oliveira PF, Martins AD, Moreira AC, Cheng CY \& Alves MG 2015 The Warburg effect revisited - lesson from the Sertoli cell. Medicinal Research Reviews 35 126-151. (https://doi.org/10.1002/med.21325)

Oliveira PF, Sousa M, Silva BM, Monteiro MP \& Alves MG 2017 Obesity, energy balance and spermatogenesis. Reproduction 153 R173-R185. (https://doi.org/10.1530/REP-17-0018)

Rato L, Alves MG, Socorro S, Duarte AI, Cavaco JE \& Oliveira PF 2012 Metabolic regulation is important for spermatogenesis. Nature Reviews: Urology 9 330-338. (https://doi.org/10.1038/nrurol.2012.77)

Rato L, Alves MG, Dias TR, Lopes G, Cavaco JE, Socorro S \& Oliveira PF 2013 High-energy diets may induce a pre-diabetic state altering testicular glycolytic metabolic profile and male reproductive parameters. Andrology 1 495-504. (https://doi.org/10.1111/j.20472927.2013.00071.x)
Rato L, Duarte AI, Tomás GD, Santos MS, Moreira PI, Socorro S, Cavaco JE, Alves MG \& Oliveira PF 2014 Pre-diabetes alters testicular PGC1- $\alpha /$ SIRT3 axis modulating mitochondrial bioenergetics and oxidative stress. Biochimica et Biophysica Acta 1837 335-344. (https://doi.org/10.1016/j. bbabio.2013.12.008)

Rato L, Alves MG, Dias TR, Cavaco JE \& Oliveira PF 2015 Testicular metabolic reprogramming in neonatal streptozotocin-induced type 2 diabetic rats impairs glycolytic flux and promotes glycogen synthesis. Journal of Diabetes Research 2015 973142. (https://doi. org/10.1155/2015/973142)

Rato L, Sousa ACA, Oliveira PF, Alves MG \& Mathur PP 2017 Sperm maturation as a possible target of obesogens. Immunology, Endocrine and Metabolic Agents in Medicinal Chemistry 17 15-31. (https://doi.org /10.2174/1871522217666170420092258)

Samuel VT, Liu ZX, Qu X, Elder BD, Bilz S, Befroy D, Romanelli AJ \& Shulman GI 2004 Mechanism of hepatic insulin resistance in nonalcoholic fatty liver disease. Journal of Biological Chemistry 27932345 32353. (https://doi.org/10.1074/jbc.M313478200)

Skakkebaek NE, Rajpert-De Meyts E, Louis GMB, Toppari J, Andersson AM, Eisenberg ML, Jensen TK, Jørgensen N, Swan SH, Sapra KJ et al. 2016 Male reproductive disorders and fertility trends: influences of environment and genetic susceptibility. Physiological Reviews 96 55-97. (https://doi.org/10.1152/physrev.00017.2015)

Sumner LW, Amberg A, Barrett D, Beale MH, Beger R, Daykin CA, Fan TWM, Fiehn O, Goodacre R, Griffin JL et al. 2007 Proposed minimum reporting standards for chemical analysis: Chemical Analysis Working Group (CAWG) Metabolomics Standards Initiative (MSI). Metabolomics 3 211-221. (https://doi.org/10.1007/s11306-007-0082-2)

Taylor R 1990 Interpretation of the correlation coefficient: a basic review. Journal of Diagnostic Medical Sonography 6 35-39. (https://doi. org/10.1177/875647939000600106)

Wang H, Wang H, Xiong W, Chen Y, Ma Q, Ma J, Ge Y \& Han D 2006 Evaluation on the phagocytosis of apoptotic spermatogenic cells by Sertoli cells in vitro through detecting lipid droplet formation by Oil Red O staining. Reproduction 132 485-492. (https://doi.org/10.1530/ rep.1.01213)

Wang TJ, Larson MG, Vasan RS, Cheng S, Rhee EP, McCabe E, Lewis GD, Fox CS, Jacques PF, Fernandez C et al. 2011 Metabolite profiles and the risk of developing diabetes. Nature Medicine 17 448-453. (https://doi. org/10.1038/nm.2307)

Whittingham DG \& Wood MJ 1983 Reproductive physiology. In The Mouse in Biomedical Research, pp 137-164. Eds HL Foster, JD Small \& JG Fox. Academic Press. (https://doi.org/10.1016/B978-0-12-2625039.50016-5)

Wishart DS, Tzur D, Knox C, Eisner R, Guo AC, Young N, Cheng D, Jewell K, Arndt D, Sawhney S et al. 2007 HMDB: the human metabolome database. Nucleic Acids Research 35 D521-D526. (https:// doi.org/10.1093/nar/gkl923)

Woodruff TJ, Carlson A, Schwartz JM \& Giudice LC 2008 Proceedings of the Summit on Environmental Challenges to Reproductive Health and Fertility: executive summary Fertility and Sterility 89 e1-e20. (https://doi. org/10.1016/j.fertnstert.2008.01.065)

World Health Organization 2000 Obesity: Preventing and Managing the Global Epidemic. Genève: World Health Organization. Available at https://apps.who.int/iris/handle/10665/42330

Wronska A \& Kmiec Z 2012 Structural and biochemical characteristics of various white adipose tissue depots. Acta Physiologica 205 194-208. (https://doi.org/10.1111/j.1748-1716.2012.02409.x)

Received 11 June 2019

First decision 4 July 2019

Revised manuscript received 23 July 2019

Accepted 22 August 2019 